Article

\title{
Manual of Cupule Replication Technology
}

\section{Giriraj Kumar $^{1, *}$ and Ram Krishna ${ }^{2}$}

1 Faculty of Arts, Dayalbagh Educational Institute, Dayalbagh, Agra 282005, India

2 BTech (EE), MBA, Faculty of Management, Dayalbagh Educational Institute, Dayalbagh, Agra 282005, India; E-Mail: ramkrishna.gem@gmail.com

* Author to whom correspondence should be addressed; E-Mail: girirajrasi.india@gmail.com; Tel.: +91-941-226-0827.

Academic Editor: Robert G. Bednarik

Received: 6 May 2015 / Accepted: 30 June 2015 / Published: 23 September 2015

\begin{abstract}
Throughout the world, iconic rock art is preceded by non-iconic rock art. Cupules (manmade, roughly semi-hemispherical depressions on rocks) form the major bulk of the early non-iconic rock art globally. The antiquity of cupules extends back to the Lower Paleolithic in Asia and Africa, hundreds of thousand years ago. When one observes these cupules, the inquisitive mind poses so many questions with regard to understanding their technology, reasons for selecting the site, which rocks were used to make the hammer stones used, the skill and cognitive abilities employed to create the different types of cupules, the objective of their creation, their age, and so on. Replication of the cupules can provide satisfactory answers to some of these questions. Comparison of the hammer stones and cupules produced by the replication process with those obtained from excavation can provide support to observations. This paper presents a manual of cupule replication technology based on our experience of cupule replication on hard quartzite rock near Daraki-Chattan in the Chambal Basin, India.
\end{abstract}

Keywords: cupule; replication; technology; manual; quartzite rock

\section{Introduction}

Rock art is a global phenomenon. It forms the archaic visual manifestations of hominins on bare rock surfaces, which have survived the vagaries of time (Kumar 2014) [1]. Throughout the world 
iconic rockart is preceded by non-iconic rock art. Cupules form the major bulk of the early non-iconic rock art (one form of paleoart) globally, and have been recorded on every continent that early humans occupied (Bednarik 2008) [2]. The antiquity of cupules in Asia and Africa extends back to the Lower Paleolithic, though their production has continued up to the present in some regions of Australia and South America (Bednarik et al. 2005; Kumar et al. 2005; Bednarik 2013; Beaumont and Bednarik 2015; Querejazu et al. 2015) [3-7].

Cupules are manmade, roughly semi-hemispherical depressions, not normally more than $\sim 10 \mathrm{~cm}$ in diameter, that were produced on hard rock surfaces by hammer stone percussion (Kumar and Krishna 2014) [8], sometimes claimed to be supplemented or replaced on softer stones by varying combinations of abrasion and incision (e.g., Clark 1958 [9]; Van Peer et al. 2003 [10]).

We have been working on early cupules in central India, especially those in the Bhanpura region in Chambal Basin on hard quartzite rock, for more than two decades. Daraki-Chattan (DC), a small and narrow cave in Indragarh Hill bearing more than 500 cupules, is the richest and therefore one of the most important Paleolithic cupule sites in the world (Kumar 1995a, 1995b, 1996) [11-13]. It was excavated for five seasons from 2002 to 2006 (Bednarik and Kumar 2004; Bednarik et al. 2005; Kumar et al. 2005; Kumar 2006, 2008, 2010a, 2010b) [3,4,14-18]. Besides the aforementioned cave, we have also discovered many cupule sites around DC and in the region (Kumar et al. 2006) [19].

\section{The Early Indian Petroglyphs (EIP) Project}

The primary rationale of the Early Indian Petroglyphs Project is to investigate claims of the occurrence of Lower Paleolithic petroglyphs in central regions of India. Other purposes of this multi-facetted and multi-disciplinary research project are to provide new data for the chronology of the Middle and Late Pleistocene hominin history of India and to investigate India's Lower Paleolithic stone tool industries. This project, a collaboration of Indian and Australian researchers, was commenced in 2000. It involves archaeological excavations, a range of analytical studies, replication work and intensive field surveys, and it will continue for several more years. Since its findings are of considerable significance to the understanding of the cognitive evolution of humans, it would not be appropriate to defer the publication of all details until after its completion. Preliminary scientific reports have appeared and although there remain important questions to be resolved, the following has been well established.

The EIP Project has demonstrated the presence of Lower Paleolithic petroglyphs in two quartzite caves in central India, and is engaged in determining the existence of further occurrences of this kind. In Auditorium Cave, at the World Heritage-listed Bhimbetka rock art complex, ten cupules and a linear petroglyph predate the late Acheulian and are very likely of an older, Oldowan-like chopping-tool tradition. In Daraki-Chattan Cave, re-discovered by R. Pancholi in 1995, twenty-eight of the more than 530 cupules on the cave's walls have exfoliated and were recovered from an excavation, together with stratified Lower Paleolithic stone tools. Even some of the hammer stones used in their production were excavated, occurring in the chopping-tool layers near the base of the sediment sequence. This rock art was created several hundred thousand years ago and is many times the age of the oldest known rock art in Europe, which is around 40,000 years old. The second-oldest currently known rock art, which is identical, occurs in southern Africa and is thought to be about four hundred millennia old (Beaumont and Bednarik 2015) [6]. On this basis, and considering that seafaring, which requires language, also 
began in Southern Asia (Bednarik 2015a) [20], it is now believed that the human ability of using symbols, our most important ability, may have first emerged in that part of the world. Africa is no doubt the cradle of humanity, but it now seems that it was in Southern Asia where complex human culture first appeared.

The EIP Project is a collaboration of the Rock Art Society of India (RASI) and the Australian Rock Art Research Association Inc. (AURA), under the aegis of the International Federation of Rock Art Organizations (IFRAO) and with the support of several agencies, including the Archaeological Survey of India, the Indian Council of Historical Research and the Australia-India Council in Canberra. The joint directors of the EIP Project are Giriraj Kumar (Indian Director) and Robert G. Bednarik (Australian Director).

\section{Understanding the Cupules Scientifically}

When one observes the cupules in the field the inquisitive mind poses so many questions to understand their creation, concerning the technology used, selection of the site and hammer stones of a particular rock type used, the skill and cognitive abilities employed to create different forms of them, the objective of their creation, their antiquity, and so on. Answers to these questions are not so simple. Plenty of untenablesuggestions were considered while we were working on the site. Hence, in 2002, we decided to commence a project of cupule replication which we thought could provide satisfactory answers to some of these questions and which, importantly, can be tested scientifically (Kumar 2008, 2010c) [16,21]. Careful comparison of the hammer stones and cupules produced by the replication process with those obtained from the excavation provided strong support for our observations. Thus, understanding of the cupule creation, in terms of specific form and size on a specific rock type, will be more secure by the replication process on rock of the same lithology than any attempt to interpret it simplistically.

\subsection{Experiments for Replication of Cupules}

Experiments to help in understanding the technology of the creation of petroglyphs, including cupules, were conducted in different parts of the world, but all were on relatively soft rocks such as weathered sandstone (Bednarik 1998, 2007) [22,23]. Bednarik himself did many such experiments. In Bolivia, in 1997, he tried to establish a "standard groove" and a "standard cupule" on heavily weathered sandstone, producing the latter in two minutes (Bednarik 2007, 43-45) [23]. However, throughout the world there is no reference of replication of cupules on hard quartzite rock till 2002 when we started our own experiments to replicate cupules near Daraki-Chattan (henceforth DC).

\subsection{Replication of Cupules on Hard Quartzite Rock Near DC}

Our work on the cupule replication project under the EIP project since 2002 (Kumar 2010a, 2010b, 2010c; Kumar and Prajapati (Ram Krishna) 2010; Krishna and Kumar 2012a, 2012b; Kumar and Krishna 2014) $[8,17,18,21,24-26]$ is still continuing. During the project many other aspects besides the technology of the creation of cupules also became clear which can be formulated as testable propositions. 
The replication of cupules helped us in understanding that their creation on hard quartzite rock is an incredibly long, arduous and labor-consuming task, involving literally tens of thousands of strokes with hammer stones. The struck rock being very hard, the hammer stone rebounds with equal force with each stroke, and gives a powerful jolt in the shoulder of the worker, especially in the creation of large circular cupules and cupules with conical sections. Hence, a person attempting the replication of cupules must have sufficient physical strength, commitment, stamina and patience. In this work, we only used hammer stones of the kind found in the excavation at DC; its cupules were created long before the introduction of metal tools.

During debate of our papers in international conferences, such as the First International Cupules Conference held in Cochabamba, Bolivia, in 2007, and personal discussions with Bednarik and Gori Tumi Echevaría López, it became clear to us that we have to prepare guidelines on cupule replication technology which can serve as a road map for anyone who is interested in experimenting with cupule replication. We recalled the entire process, the problems faced, decisions taken to meet the challenges and the progress made. Here we try to develop a manual of cupule replication technology on the basis of our practical experience on hard quartzite rock.

\section{Objectives of the Replication of Cupules}

\subsection{Predefined Objectives}

First of all we must be very clear of the objectives of replication of cupules. Why was such a tedious and labor-intensive task as cupule production undertaken? Without existing guidelines for quantifying the process we had to develop our own, designing the parameters to work within. When we were working at DC (Figures 1-3), Stone Age archaeologists visited the site and gave "authoritative" opinions about the creation of cupules, such as by "scooping" of the rock, rotating a hard object left and right on the rock and so on. Quartzite rock being so hard (Mohs scale 7, which is 4000 times as hard as 1 on Mohs scale), we could not accept their untenable suggestions, nor did their pronouncements agree with the relevant specialist literature. Hence, to replicate the cupules was the only way to understand cupule technology scientifically.

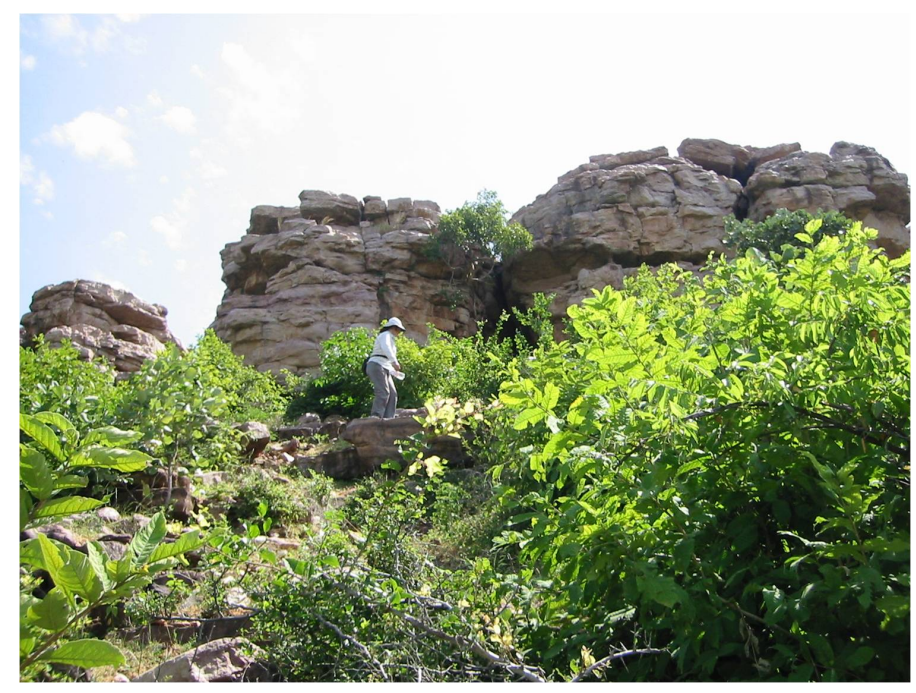

Figure 1. Daraki-Chattan Cave (DC) in the quartzite buttresses of Indragarh hill. 


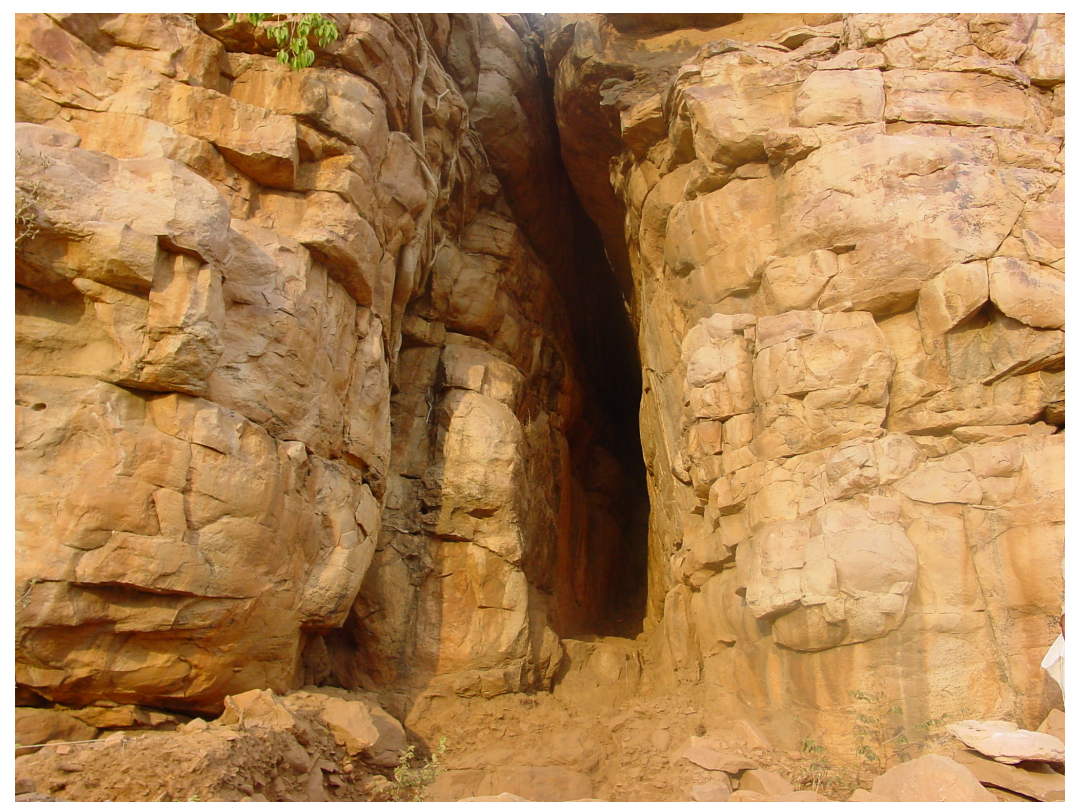

Figure 2. Daraki-Chattan cave (DC) from the front.

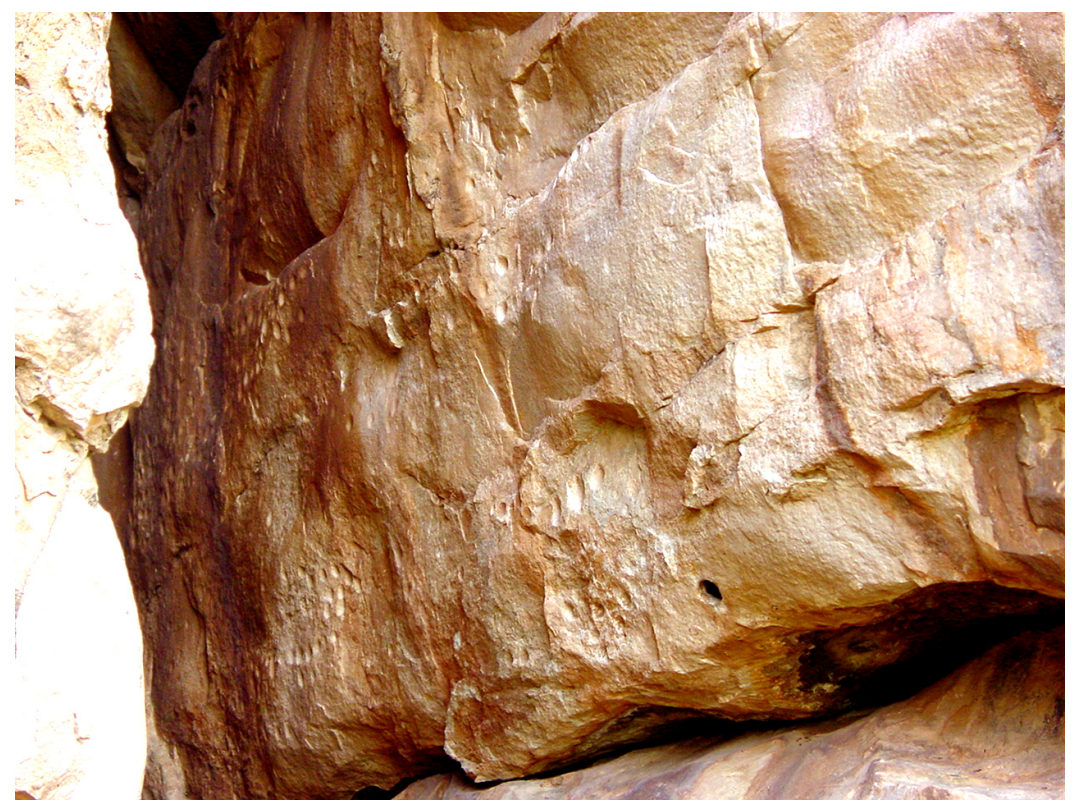

Figure 3. Daraki-Chattan cave (DC) southern wall with front portion devoid of cupules because of weathering.

\subsection{Unknown Objectives}

Besides the predefined objectives one can also achieve some other, unexpected, results, such as conditions an experimenter has to meet, the possible motivation behind the creation of cupules on hard quartzite rock, etc. However, to reach any credible conclusion one must be free of preconceptions and capable of recording the data without presuming their implications. 


\section{What to Observe}

Observations to be made in a cupule site should include:

(1) Hardness and nature of rock (lithology).

(2) Cupule shape, maximum and minimum rim diameter, maximum depth, depth-to-mean-diameter ratio, and cupule volume (as described in Bednarik 2016) [27].

(3) Exfoliation of rock surface adjacent to the cupules and weathering both in and near the cupules are important factors to be studied. If laminar exfoliation has occurred around a cupule, it has acquired a new rim and has lost much of its depth.

(4) Microscopic examination of the cupules' surface condition, considering retreat of cement, extent of granular exfoliation, presence or absence of crushed or fractured quartz grains.

(5) State of patination and mineral accretions on the cupules and the rock surface surrounding them. It must be noted that accretions may have experienced phases of accumulation and exfoliation (in dry periods) or removal by rainwater or runoff.

(6) Presence of evidence of kinetic energy metamorphosis (KEM) on cupule floors (Bednarik 2015b) [28].

(7) Ambient environmental data, such as climate, air temperature and rock temperature in different seasons of the year.

\section{Observations to Be Made in the Process of Cupule Replication}

Crushing of crystals of the rock in the process of pounding to create a cupule, resulting in whitish powder of removed rock mass.

(1) The size and pattern of fracture at and near the point of the hammer stone are important factors for identifying ancient hammer stones.

(2) Correlation of the characteristics of ancient hammer stones (from excavation or surface finds) with those used in the process of cupule replication, as per factors 1 and 2 .

(3) Observe signs of change in hardness of the struck surface of the cupule. This occurs because of tribological changes in the properties of the voids sealed off by syntaxial quartz overgrowths and is due to cumulative kinetic energy impact (Bednarik 2015b) [28]. Thus, it becomes comparatively harder to remove rock mass during the process of deepening a cupule. The hard surface so developed has been found quite resistant to weathering as compared to the parent rock (Figure 6).

(4) Ambient temperature of the rock has to be recorded by digital laser thermometer, on the cupule surface during application of hammer stones, and compared to the temperature of the adjacent rock.

\section{Selection of the Rock for Experiment}

The lithology and hardness of the rock bearing archaic cupules and those of the rock on which the cupule replication work is to be carried out must be the same. Therefore, we selected a hard quartzite bedrock surface, slightly tilted from the vertical, of a small rock shelter by the left (southern) side of 
and immediately close to DC for our replication experiments, because it is a continuation of the bedrock of DC, hence it is of the same lithology (Figure 4). Most of the cupules in DC are on the fully vertical walls of the cave.

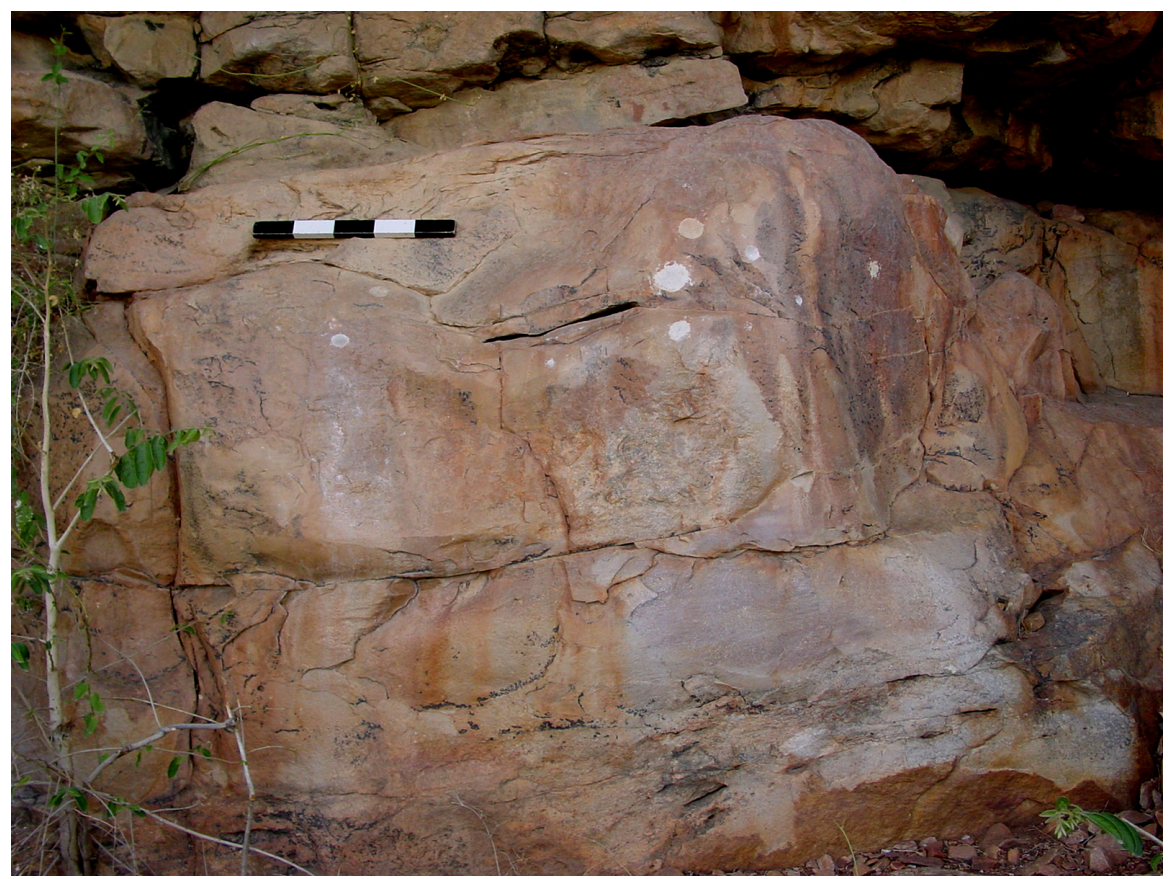

Figure 4. Experimental rock by the southern side of DC for replication of cupules.

\section{Process of Cupule Replication}

\subsection{Observation of Cupules in DC}

In DC, we observed four kinds of cupules by creating a subjective taxonomy, which may or may not be significant:

(1) Large circular cupules with saucer-shaped or more convex round floor.

(2) Small circular cupules with conical section (highly convex at nadir). Oval or oblong cupules are a combination of the two cupules of category two.

(3) Small circular cupules with deep smooth floor and diameter around $25 \mathrm{~mm}$ only. In DC, there are only two of them on the northern wall (NR No. 144, $24.65 \times 27.0 \times 11.35 \mathrm{~mm}$; and NR No. 162 , $24.5 \times 23.8 \times 8.83 \mathrm{~mm}$; and one on the southern wall (SR No. $195 \mathrm{~b}, 32.3 \times 24.6 \times 8.4 \mathrm{~mm}$ ).

(4) Small cupules with angular periphery and angular section (Figures 5-10).

(5) Thus, we have to decide which kind of cupule we are going to replicate. 


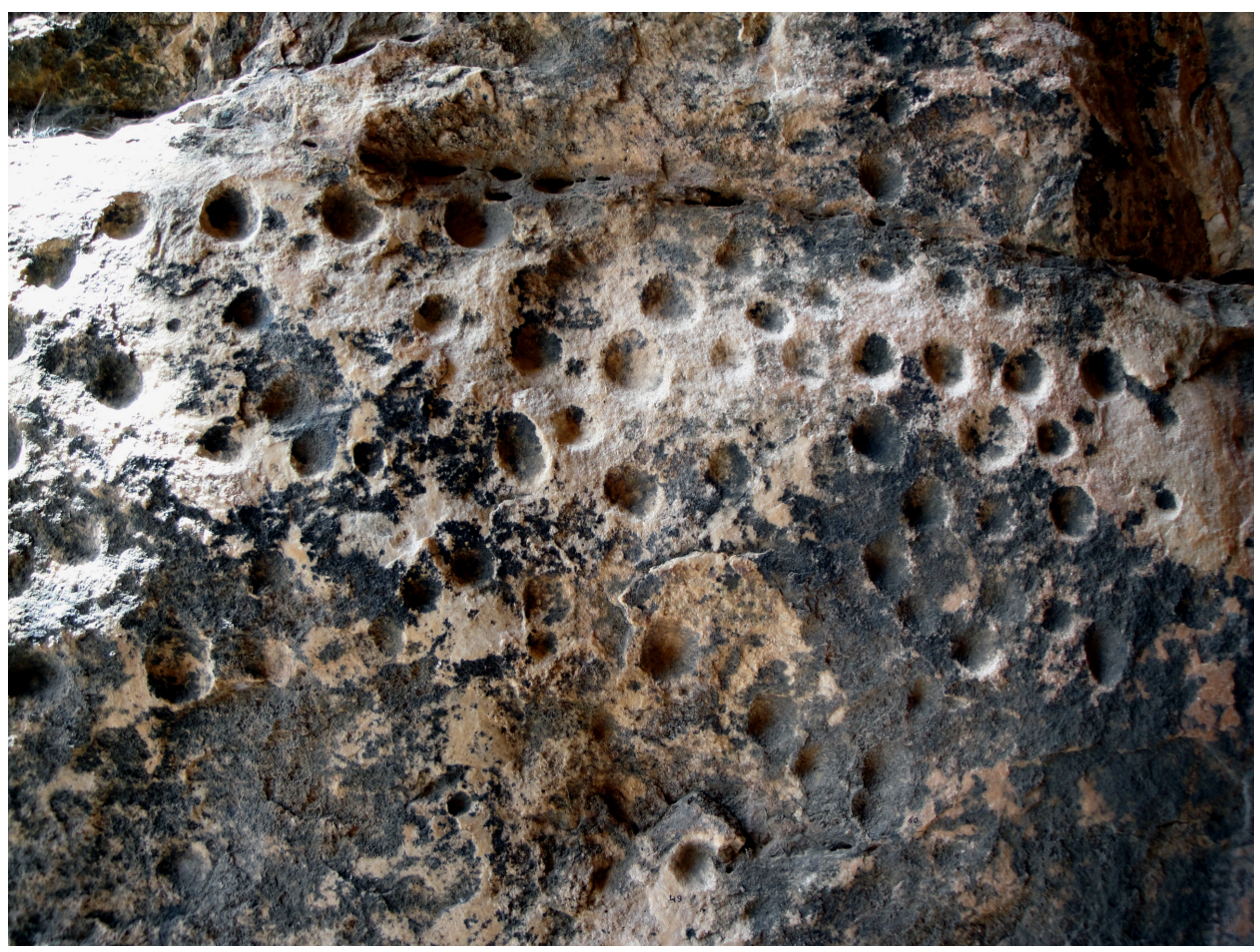

Figure 5. Big saucer shaped cupules in DC.

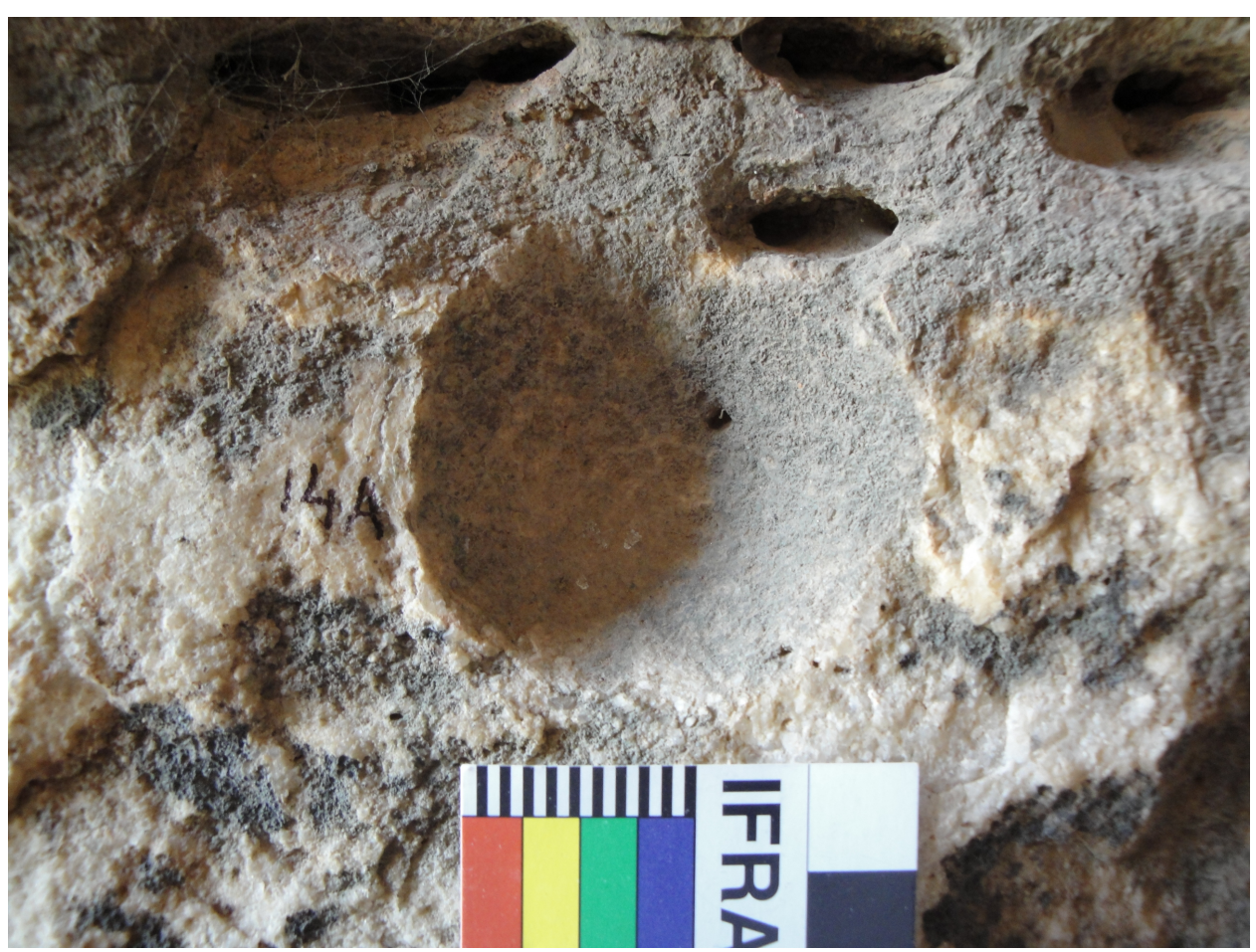

Figure 6. Big deep cupule in DC. 


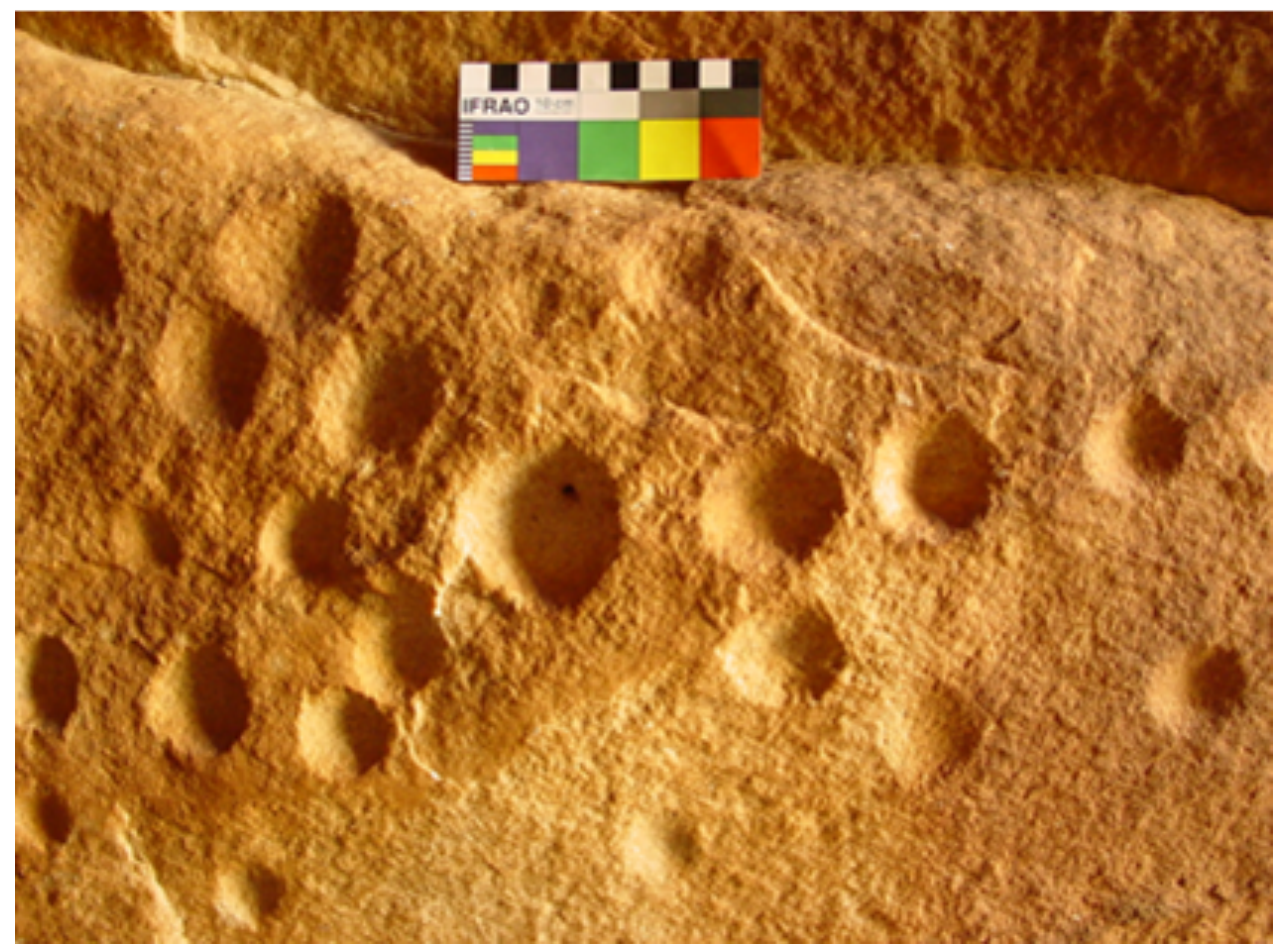

Figure 7. Small cupule with conical depth (section) in DC.

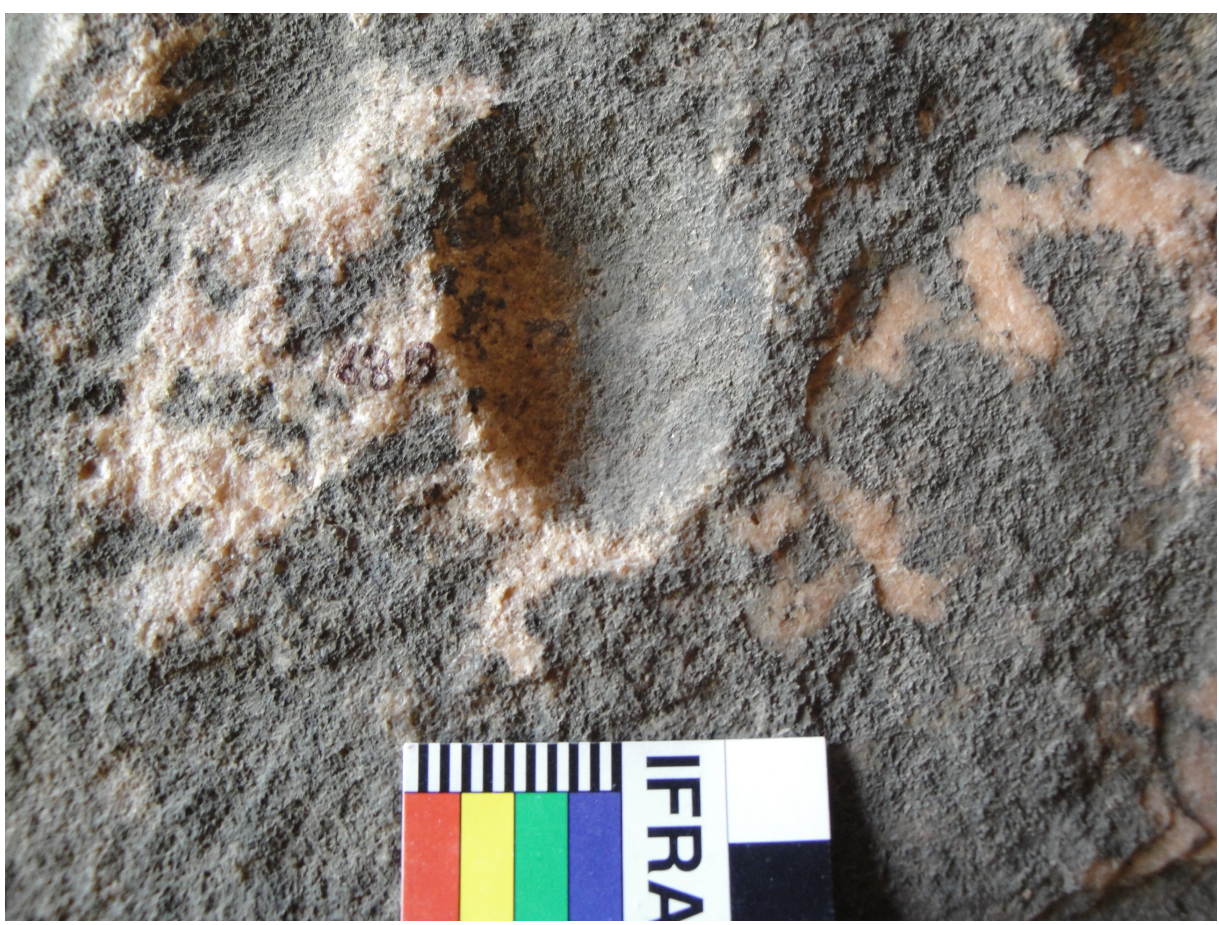

Figure 8. Oval shaped cupule on northernwall in DC. 


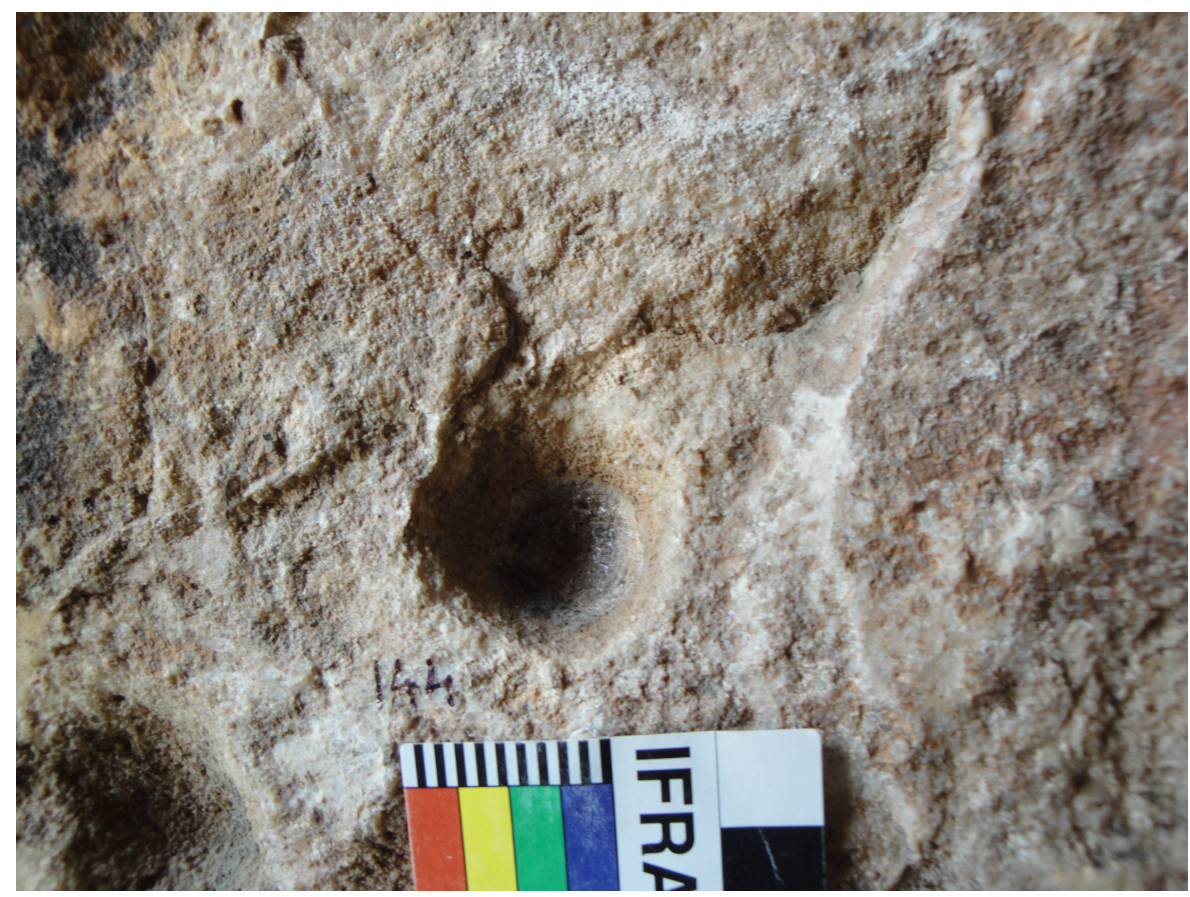

Figure 9. Very small cupule with conical depth (section) in DC.

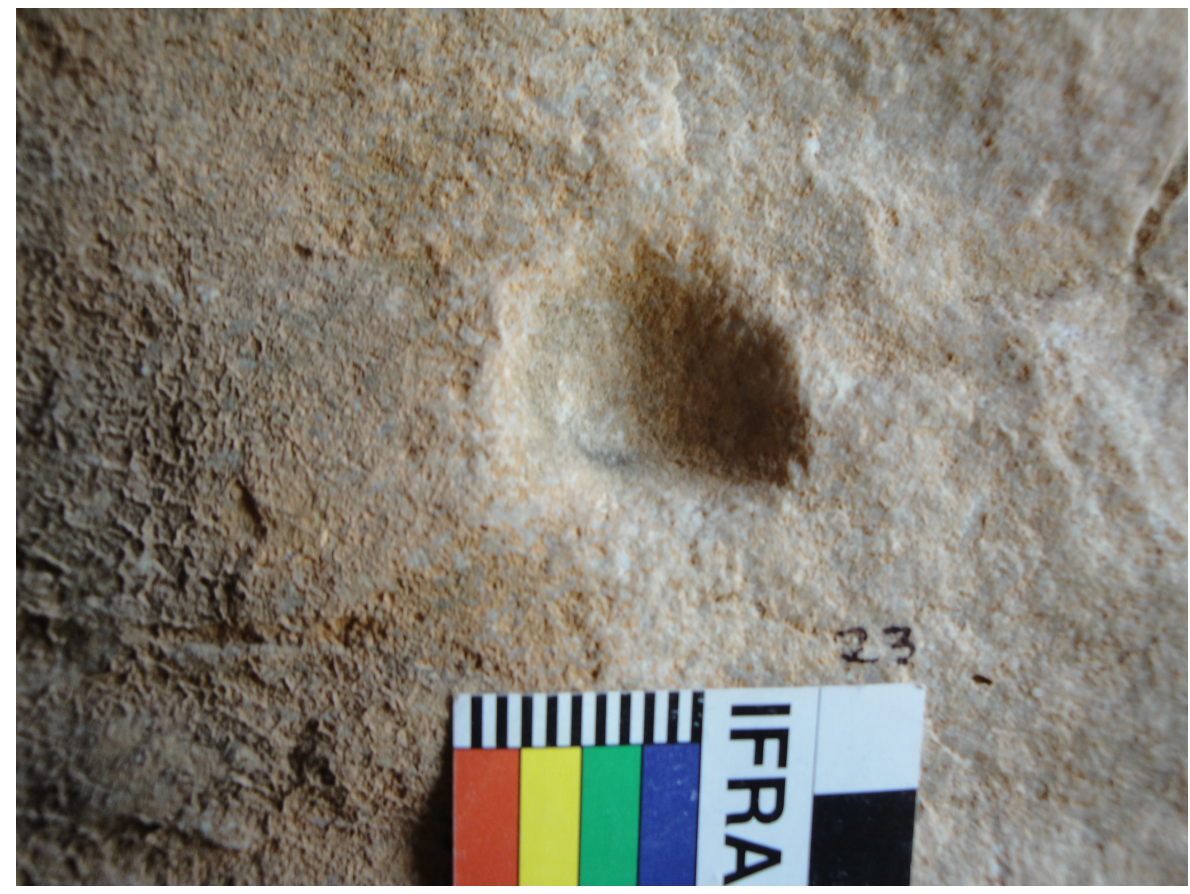

Figure 10. Small cupule with roughly triangular periphery and depth on southern wall in DC.

\subsection{Selection of Suitable Cobbles for Hammer Stones}

Once it has been established what kind of cupule is to be replicated, the task of selecting suitable cobbles/pebbles to be used as hammer stones derives from this decision. For replicating each kind of cupule, different types of hammer stones are required, all of them of the same hardness as the bedrock in the case of DC (hardness 7 on Mohs scale). From the excavations at DC, we observed that cobbles with a purple core were used for hammer stones. We observed that such cobbles are available in 
Patasighati, a paleochannel on the east side of Indragarh Hill, the opposite side of DC, a few hundred meters from the cave. We also tried to use chert and chalcedony cobbles as hammer stones, but we found them to be too fragile and not suitable to serve as hammer stones.

For producing different kinds of cupules like those in DC, different types of cobbles were used as hammer stones. For big circular cupules with saucer-shaped or deep-rounded floor (cupules of more than $50 \mathrm{~mm}$ diameter and more than $5 \mathrm{~mm}$ depth), cobbles with a tapering head to be used as striking end are used, of suitable shape to allow a strong grip. For small circular cupules with conical depth, cobbles with one or more angular heads are used, also of suitable shape to provide a strong grip.

\section{The Replication Process}

\subsection{How to Begin Replication Work}

Cobbles to be used as hammer stones are given proper numbers and photographs are taken of both their obverse and reverse side before they are used. Photographs are also taken of the site in full view, then the rock and the surface on which the desired cupule is going to be replicated. Photographs of the site are to bear range poles, for other purposes the $10 \mathrm{~cm}$ IFRAO Standard Scale should be used for the purpose of color calibration.

Each member of the team should keep a diary to make notes of all the actions, observations and any ideas that come to mind. After finishing, the fieldwork of the day all the information and observations in the field note books with all minute details are shared at our base camp. In the work at DC, we share and discuss the experience of our practical work with our team every day and also during the ongoing process of cupule replication work. It is necessary to find out the solutions of the problems faced, such as if hammer stones are suitable for work, is there any problem with time keeping of the strokes, are we making the efforts in right direction, etc.

\subsection{Tool Kit Required}

We need an appropriate tool kit for working in the field. It must have basic tools, such as a compass, magnifying glass, small brushes (as used for painting) and also a brush three to five cm wide for brushing the surface and collection of the samples. We must also have aluminum foils to collect the samples of the powder of the crushed crystals and chips removed during the replication process, and double-sided tape to fix it on the rock surface if needed.

We must have a device to keep the time of the cupule replication process and at least two or more cameras to record the process and stages in cupule replication. Also needed in future work, is a digital laser thermometer. It is necessary to minimize the chance of losing any data due to technical problems.

\subsection{How to Replicate a Cupule}

From the very beginning we did not know how the cupules were made, and we distinguish at least four kinds of cupules in DC. We learned about cupule production gradually during the process of replication itself.

In 2002, we just proceeded to replicate a first cupule. We used direct percussion technique and powerful strokes with relatively large cobbles, resulting in a big cupule of category 1 (Figures 11 and 
12). Then, we thought of reducing the diameter of the replicated cupule as suggested in the literature (small cobbles, average weight $160 \mathrm{~g}$; Bednarik 2008) [2]. In the process we learned to use small hammer stones with multiple striking heads. Thus, the experiment was the real teacher. However, we were cautious and ready for deviations and correcting actions in the process. For example, we were not aware initially that multiple small hammer stones were required to create a small cupule with conical section and that hammer stones have to be changed repeatedly.

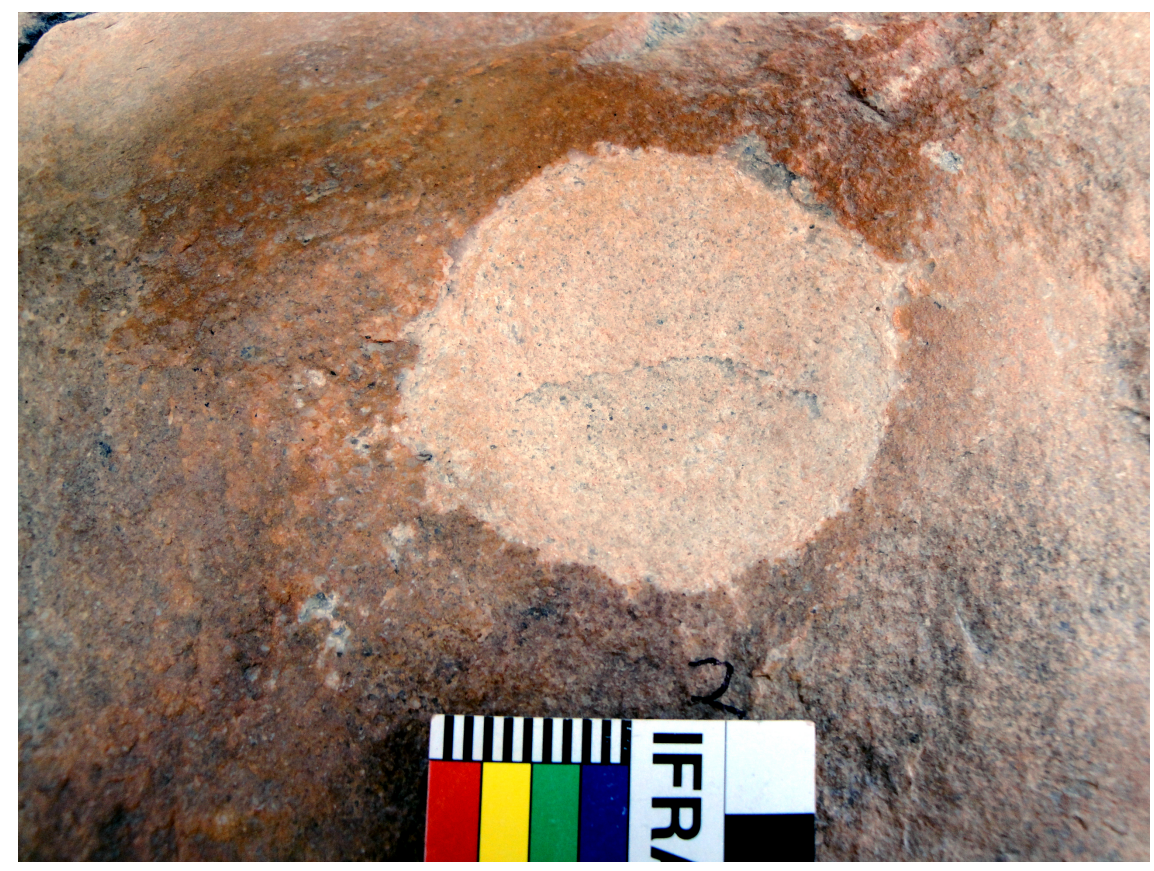

Figure 11. Replicated saucer shaped cupule, RC-2.

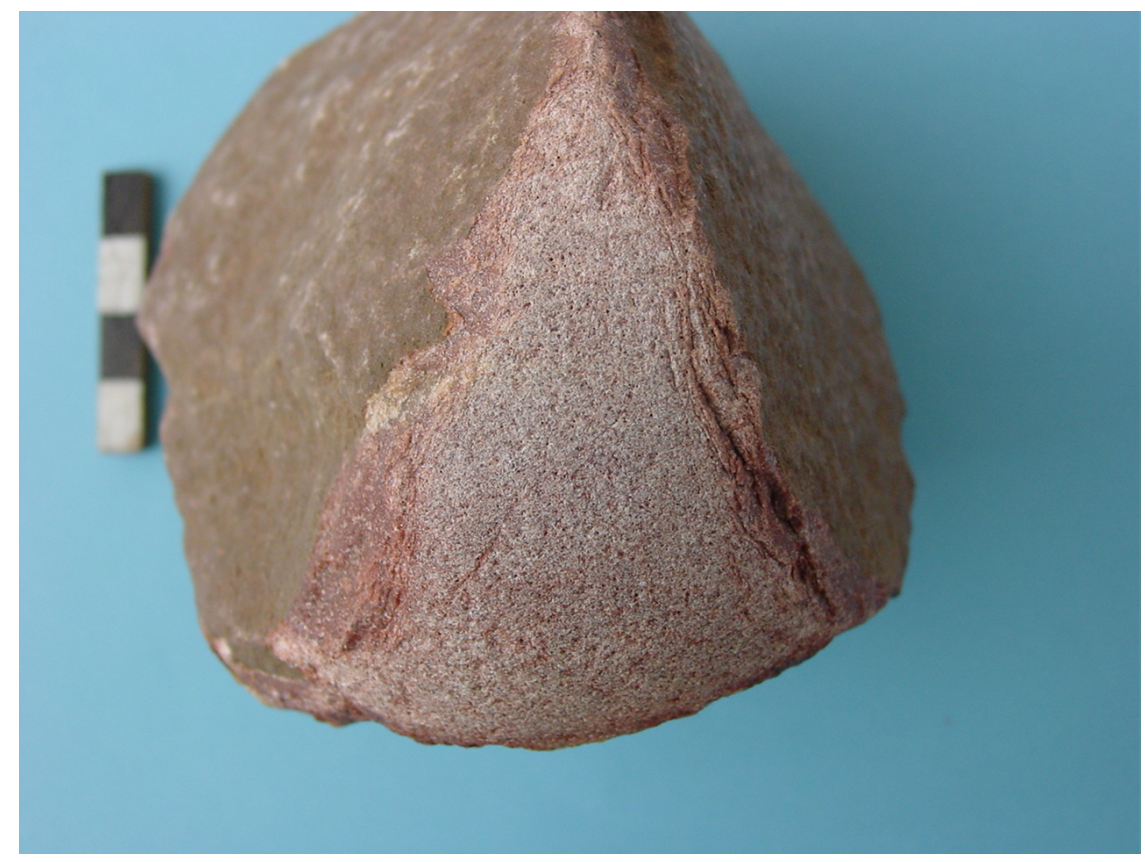

Figure 12. Hammer stone on hard quartzite cobble used for making RC-2. 


\subsection{How a Conical Section is Produced}

Once the area of striking was marked out after a few thousand strokes, the process of deepening the cupule began. After achieving a certain depth with one hammer stone we needed to change it for a fresh one with a small stout point, or use a different head of the same hammer stone. Now strokes started bruising the floor of the incipient cupule in the center, thus increasing depth of the replicated cupule. After its use for some time, the head of the hammer stone becomes blunt and starts removing mass from the sides of the cupule, thus increasing diameter rather than depth. Thus, to increase depth without affecting diameter, the hammer stone has to have a pointed section and must be changed frequently (Figures 13-15).

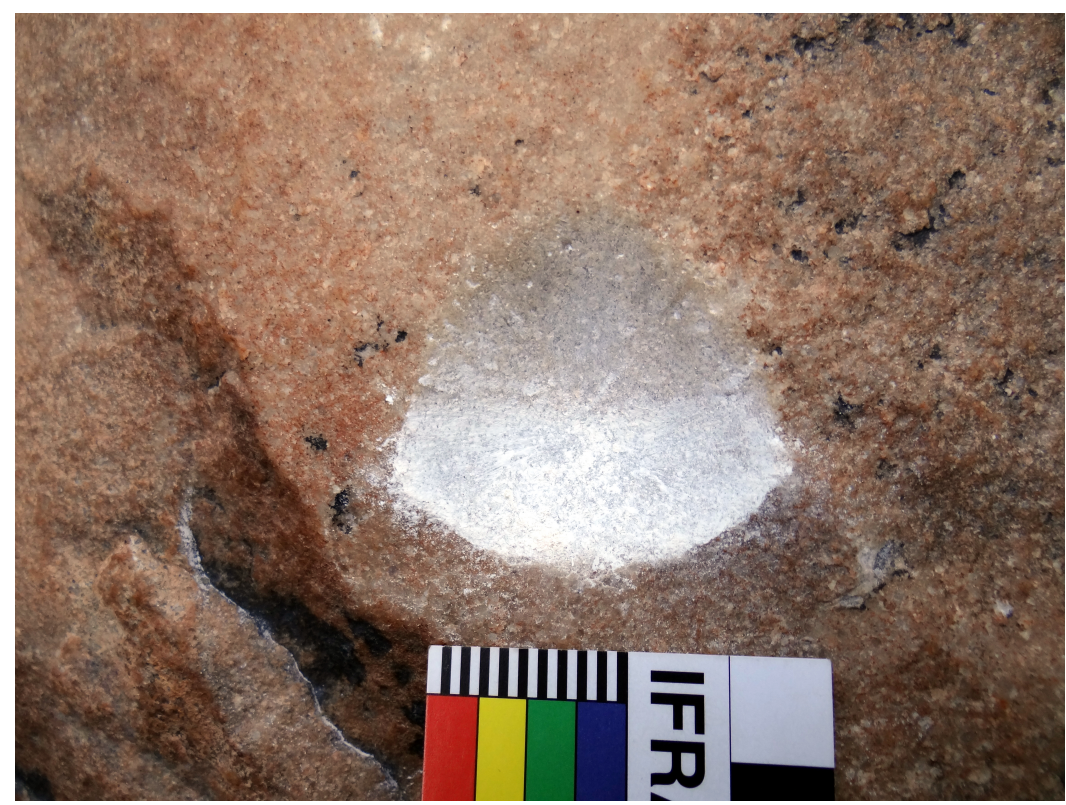

Figure 13. Replicated small cupule with conical depth, RC-9.

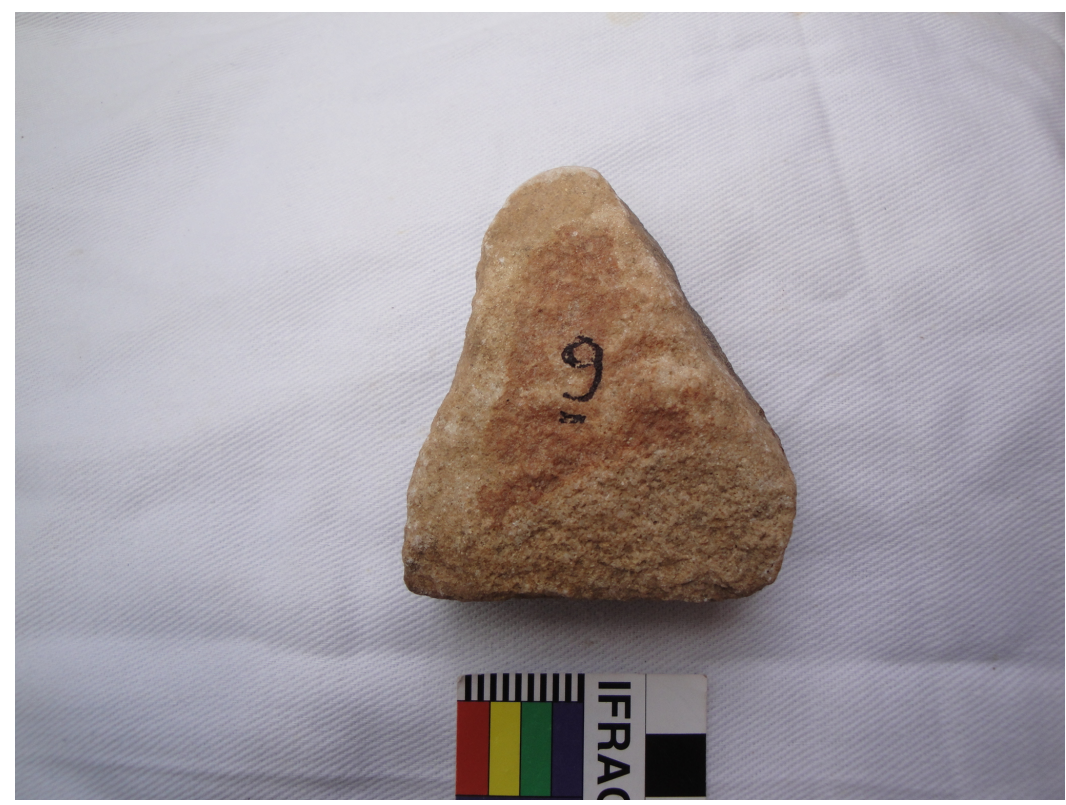

Figure 14. Hammer stone on hard quartzite cobble used for making RC-9. 


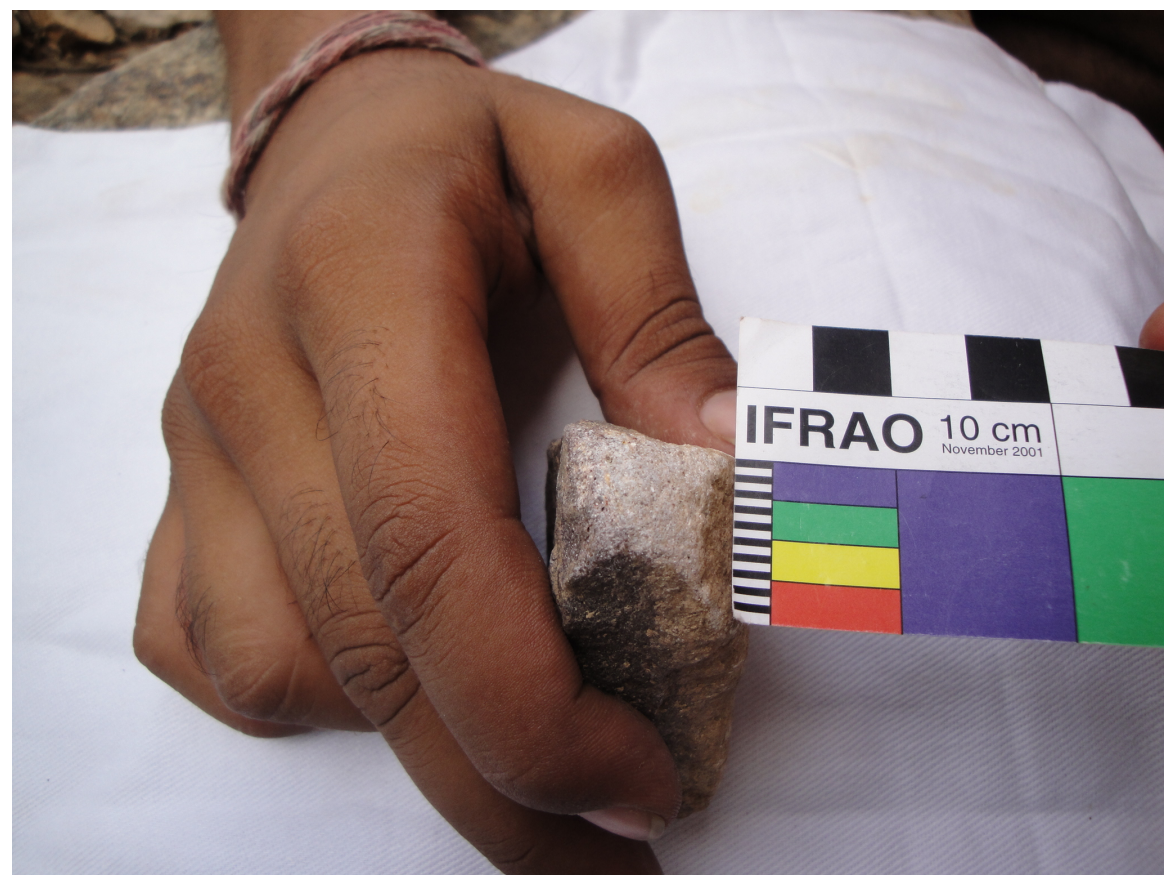

Figure 15. Striking head of the hammer stone on hard quartzite cobble used for making RC-9.

\subsection{Oval or Oblong Cupules}

Our observation of the cupules in DC indicate that such cupules are made by joining two small circular cupules with conical section and overlapping peripheries as we can see in cupule No. $68 \mathrm{~b}$ on the northern wall of DC. Hence, hammer stones and techniques used for their production are almost the same as those for small circular cupules with conical depth.

Small circular cupules with deep smooth floor are difficult to produce by direct percussion technique. However, we have to check this. In DC such a kind of cupules is very small and rare. There are only two of them on the northern wall (NR No. 144, $24.65 \times 27.0 \times 11.35 \mathrm{~mm}$; and NR No. 162, $24.5 \times 23.8 \times 8.83 \mathrm{~mm}$; and one on the southern wall (SR No. $195 \mathrm{~b}, 32.3 \times 24.6 \times 8.4 \mathrm{~mm}$ ).

\subsection{Small Cupules with Angular Periphery and Deep Angular Section}

The problem of replicating small cupules with angular periphery and angular section was puzzling. We observed and studied the cupules in DC very carefully again and again and discussed them for two days to reach the conclusion to develop a hypothesis that a roughly triangular or roughly square shape of cupules appears to have developed from circular cupules with conical depth. If we shift the center of the depth, the cupule form will change to angular form. It was only then that we proceeded to test this idea. To produce an angular cupule RK used soft strokes with a thin and elongated cobble from both its the ends and lifting the hand only up to 5-6 cm during strokes (Krishna and Kumar 2012b; Kumar and Krishna 2014) [8,26] (Figures 16-19). 


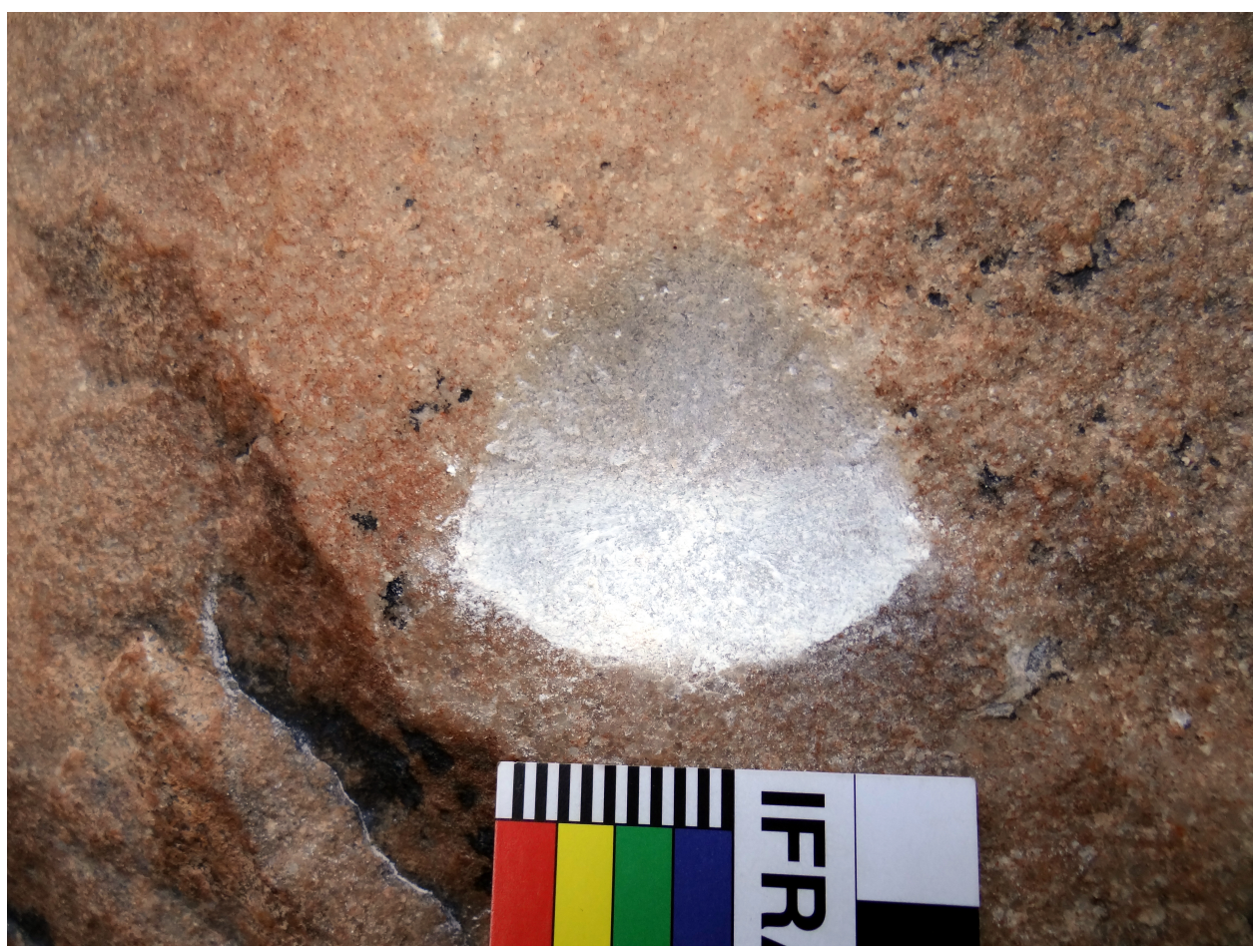

Figure 16. Replicated small cupule RC-10, with roughly triangular shape and depth.

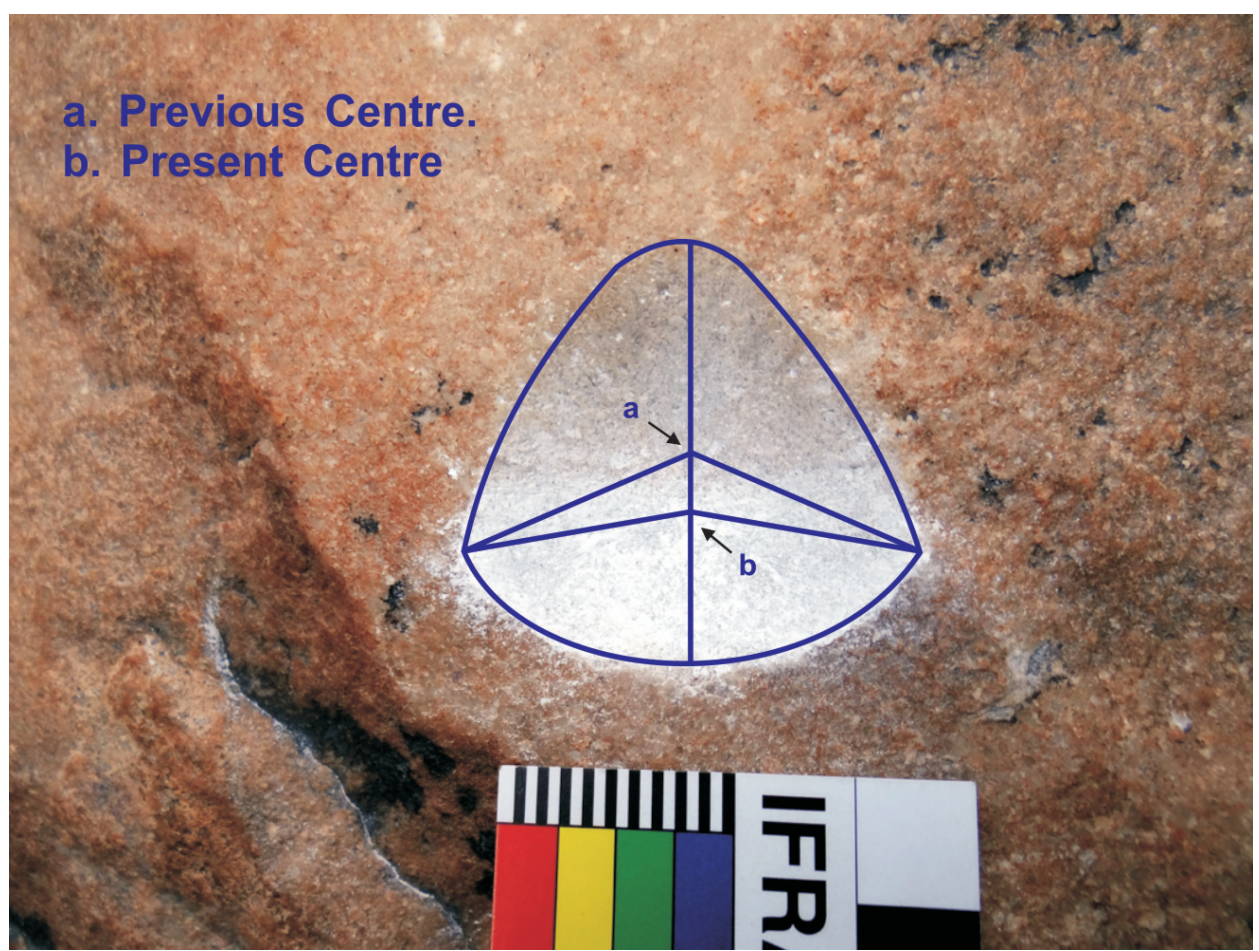

Figure 17. Figure showing the shifting of central point downwards in the roughly triangular RC-10. 


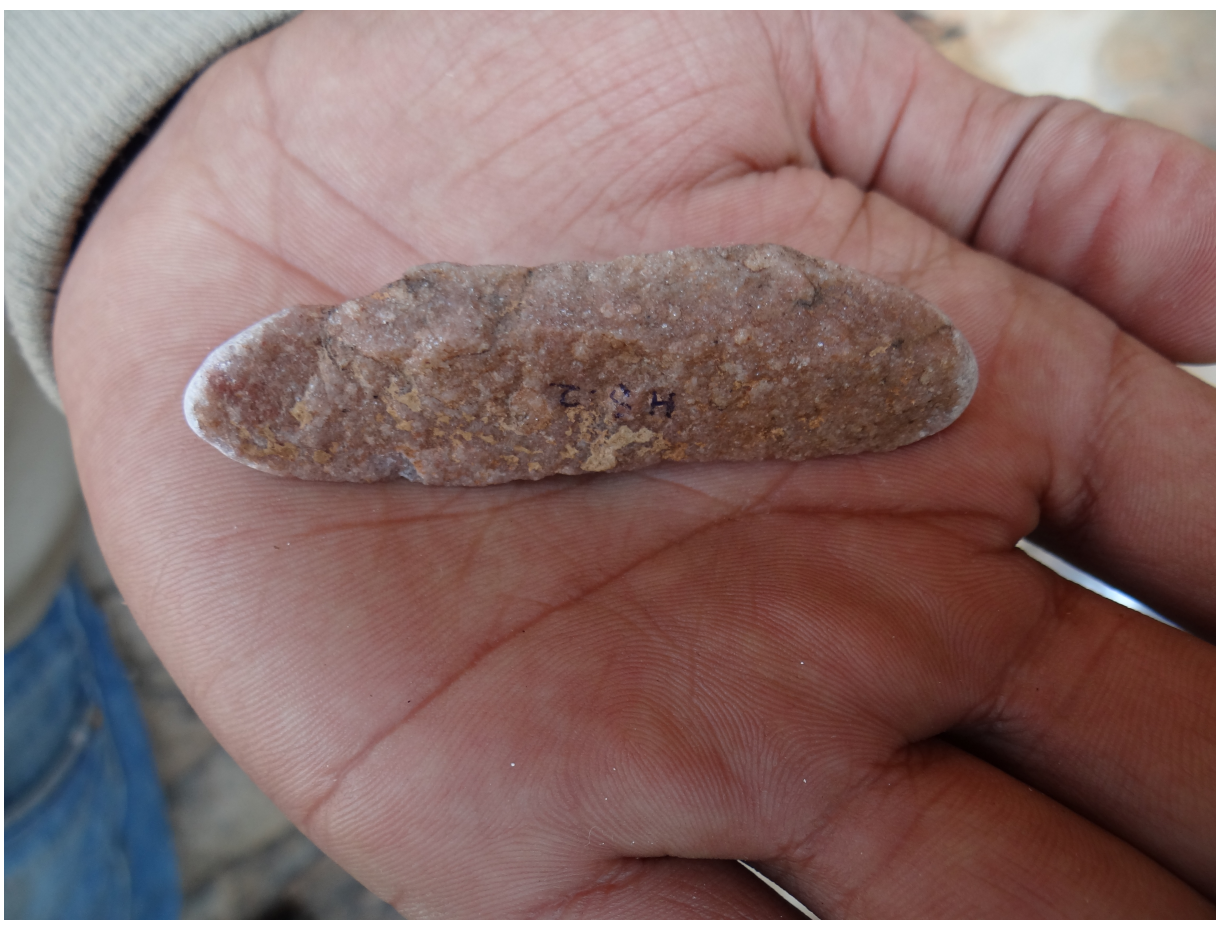

Figure 18. Small and elongated quartzite flake used as hammer stone from its both the ends to produce RC-10.

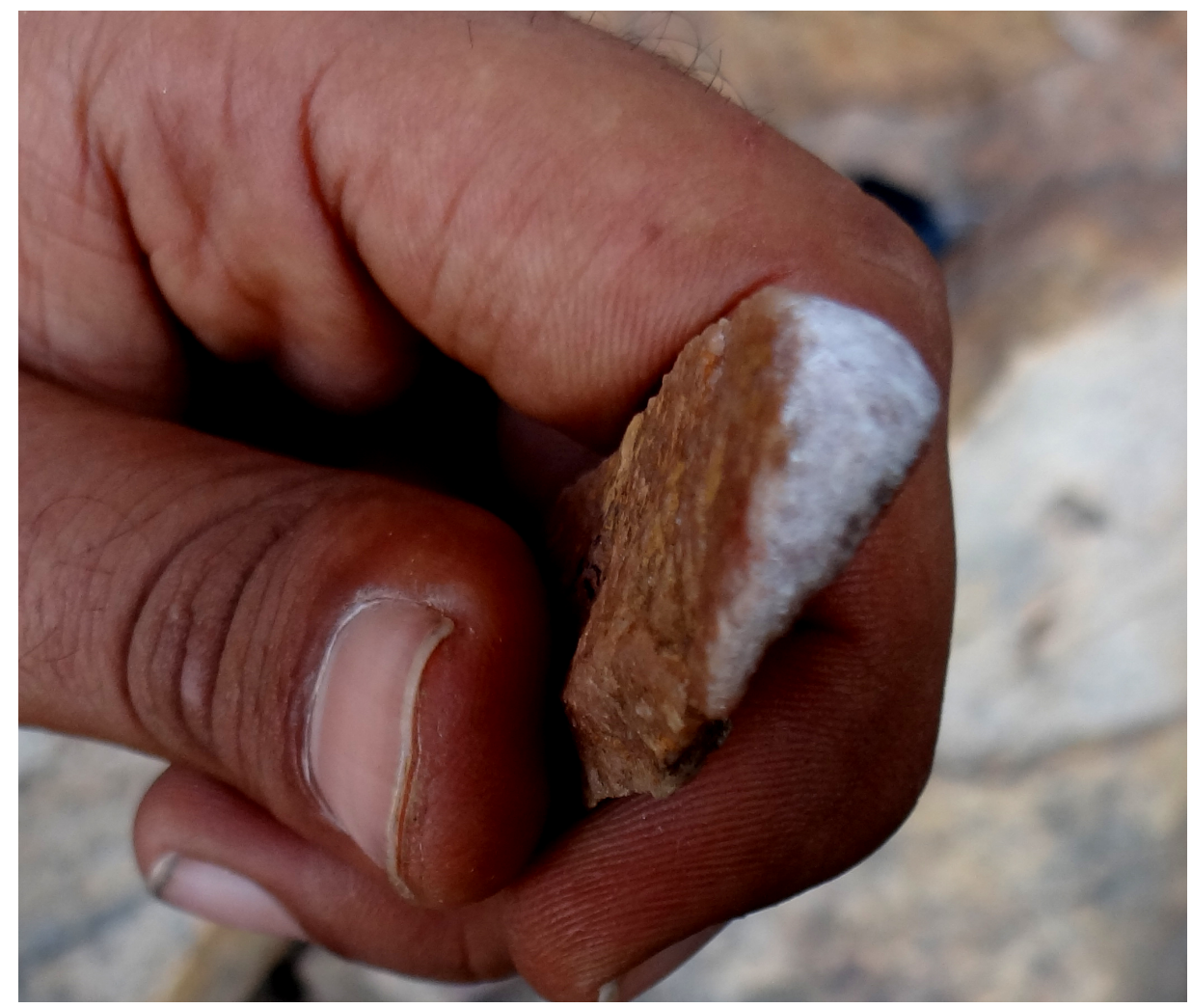

Figure 19. Striking head of the hammer stone (Figure 18) used to produce RC-10. 


\subsection{Management of Time and Energy}

For understanding the progress of cupule creation we have to manage time and energy needed to create a desired cupule. Hence, we recorded the number of strokes in several phases of set time duration (such as 2, 5, 10 or $15 \mathrm{~min}$ ) in the field notebook. One person (generally Kumar) was keeping time with the clock in our mobile, while another (generally Krishna) was working on replication of the cupule.

As we lacked the means of properly measuring the energy expended, or made no attempt to calculate it, we simply noted the height up to which the experimenter needed to lift his hand for executing the strokes of desired force and precision.

\subsection{Recording of the Process}

Recording of every step of the replication process on the field diary and by photography is essential. If one has the facility, recording through video of the whole process will be useful as well.

We also observed and recorded other aspects, such as chipping patterns on the hammer stones, the quality of stroke (hard and powerful, gentle and controlled), the height up to which the hand was lifted to execute the desired strokes, etc. During the process of cupule replication, it is also necessary to observe factors that can affect the concentration of the experimenter.

\section{Understanding the Techniques Used for Cupule Replication}

For creating big cupules of category 1 we needed two or three big hammer stones on cobbles, while for creating small cupules of category 2 we had to use multiple small hammer stones on cobbles/ pebbles and needed to change them repeatedly. It implies that the size of the hammer stones to be used is directly proportional to the size of the cupule replicated, while the number required is indirectly proportional. Similarly the number of strokes used is indirectly proportional to the size of the cupules. At the same time, the force exerted in a stroke is directly proportional to the size of the hammer stone; the bigger the size of hammer stone, the more powerful the stroke. The energy per stroke goes on reducing with reducing the size of the hammer stone: the smaller the size of hammer stones, the softer the strokes.

\section{Conditions a Good Experimenter Must Meet}

A good experimenter must be enthusiastic and devoted to objectivity. In order to carry out the experiment of replication s/he must have patience, great dedication and a capability of original thinking. Minute observations of the site and the cupules and asking many questions from oneself for their understanding, is the key to proceed in the right direction for cupule replication. It is always better to work in a team of scholars from different disciplines, particularly from physics, epistemology and geology.

The experimenter must meet the challenges arising during the replication process and make deviations and correcting actions in the process wherever necessary. For example, we were not aware initially that multiple small hammer stones were required to create a small cupule with conical section and that the hammer stones have to be changed repeatedly. 
From our experiments, we learned that to keep the diameter small as far as possible while gaining the greatest possible depth of a cupule requires the person conducting the work to be highly focused to apply the strokes with the needed precision. The experimenter cannot afford even one wrong stroke in a thousand, as it will increase the diameter of the cupule.

\section{Conclusions}

Cupules form the bulk of non-iconic rock art in the world. Cupule replication is a scientific process for understanding many questions one has in mind concerning their production. It also implies that cupule creation by different forms by early humans appears to be related to cultural development deeply embedded in the cognitive development in hominins (Kumar and Krishna 2014) [8]. The results obtained and conclusions derived from experimentation can be tested at any time by anyone whosoever desires so in future. Thus, understanding the cupules through their replication is more secure than any attempt to interpret them simplistically on the basis of intuition.

Here, we have presented a simple manual of cupule replication on hard quartzite rock based on our experience for the benefit of scholars who want to experiment with cupule replication, and to provide an initial basis for standardization of such studies. We hope for necessary feedback in refining the process.

\section{Acknowledgments}

We are thankful to Gori Tumi Echevarría López for his interest in conducting replication of cupules in Peru; and to Robert G. Bednarik for his constructive suggestions to advance a framework for such a paper on developing a rationale for cupule replication, and for his revisions to our draft. These scholars were the inspiring force to prepare this paper, which presents guidelines for colleagues interested in studying rock art scientifically through replication work.

\section{Author Contributions}

Both authors contributed equally to the manuscript.

\section{Conflicts of Interest}

The authors declare no conflicts of interest.

\section{References}

1. Kumar, G. Rock Art. In History of Ancient India, Volume I: Prehistoric Roots; Chakrabarti, D., Lal, M., Eds.; Vivekanand International Foundation and Aryan Books International: New Delhi, India, 2014; pp. 301-346.

2. Bednarik, R.G. Cupules. Rock Art Res. 2008, 25, 61-100.

3. Bednarik, R.G.; Kumar, G.; Watchman, A.; Roberts, R.G. Preliminary results of the EIP Project. Rock Art Res. 2005, 22, 147-197.

4. Kumar, G.; Robert, G. Bednarik, Alan Watchman and Richard G. Roberts, The EIP Project in 2005: A progress report. Purakala 2005, 14-15, 13-68. 
5. Bednarik, R.G. Pleistocene palaeoart of Africa. Arts 2013, 2, 6-34.

6. Beaumont, P.B.; Bednarik, R.G. Concerning a cupule sequence on the edge of the Kalahari Desert in South Africa. Rock Art Res. 2015, 32, 163-177.

7. Querejazu, R.; Camacho, D.; Bednarik, R.G. The Kalatrancani Petroglyph Complex, central Bolivia. Rock Art Res. 2015, 32, 219-230.

8. Kumar, G.; Krishna, R. Understanding the technology of the Daraki-Chattan cupules: The cupule replication project. Rock Art Res. 2014, 31, 177-186.

9. Clark, J.D. The Chifubwa Stream rock shelter, Solwezi, Northern Rhodesia. S. Afr. Archaeol. Bull. 1958, 13, 21-24.

10. Vanpeer, P.; Fullagar, R.; Stokes, S.; Bailey, R.M.; Moeyersons, J.; Steenhoudt, F.; Geerts, A.; Vanderbeken, T.; de Dapper, M.; Geus, F. The Early to Middle Stone Age transition and the emergence of modern human behaviour at site 8-B-11, Sai Island, Sudan. J. Hum. Evol. 2003, 45, 187-193.

11. Kumar, G. Daraki-Chattan: A Palaeolithic cupule site in India. Purakala 1995, 6, 17-28.

12. Kumar, G. Petroglyphs in the Rock Art of Chambal Valley and Aravalli Hills: A New Phenomenon. In Proceedings of the Symposium 14D: News of the World, News 95 International Rock Art Conference, Turin, Italy, 30 August-6 September 1995; CeSMAP: Pinerolo, Italy, 1995.

13. Kumar, G. Daraki-Chattan: A Palaeolithic cupule site in India. Rock Art Res. 1996, 13, 38-46.

14. Bednarik, R.G.; Kumar, G. EIP Project second report. Rock Art Res. 2004, 21, 107.

15. Kumar, G. A preliminary report of excavations at Daraki-Chattan. Purakala 2006, 16, 51-55.

16. Kumar, G. Lower Palaeolithic petroglyphs from excavations at Daraki-Chattan in India. In Pleistocene Palaeoart of the World; Robert, G., Hodgston, D., Eds.; Bar International Series 1804: Oxford, UK, 2008; pp. 63-75.

17. Kumar, G. Recent Developments in Rock Art Research in India with Special Reference to the EIP Project. In Pictures in Transformation: Rock art Research between Central Asia and the Subcontinent; Olivieri, L.M., Bruneau, L., Ferrandi, M., Eds.; Bar International Series 2167: Oxford, UK, 2010.

18. Kumar, G. Cognitive and Creative Abilities of Lower Palaeolithic. Hominins in India; FundacaoMuseo Do Homen Americano, FUMDHAMentos: Capivara, Brasil, 2010; Volume 2, pp. 187-195.

19. Kumar, G.; Bhatt, P.K.; Pradhan, A.; Krishna, R. Discovery of early petroglyphs in Chambal valley, Madhya Pradesh. Purakala 2006, 16, 13-34.

20. Bednarik, R.G. The First Mariners, 3rd ed.; Bentham Books: New York, NY, USA, (1st ed. Research India Press: 2nd ed. Lambert Academic Publishing), 2015.

21. Kumar, G. Understanding the Creation of Early Cupules by Replication, with Special Reference to Daraki-Chattan in India. In Proceedings of the Mysterious Cup Marks: Proceedings of the First International Cupule Conference, Cochabamba, Bolivia, 17-23 July, 2007; Querejazu, R., Robert, R., Bednarik, G., Eds.; AEARC: Cochabamba, Bolivia, pp. 59-66.

22. Bednarik, R.G. The technology of petroglyphs. Rock Art Res. 1998, 15, 23-35.

23. Bednarik, R.G. Replicative Experiments. In Rock Art Science: The Scientific Study of Palaeoart, 2nd ed.; Aryan Books International: New Delhi, India, 2007; pp. 43-45. 
24. Kumar, G.; Prajapati, R.K. Understanding the Creation of Cupules in Daraki-Chattan, India; Fundacao Museo do Homen Americano, FUMDHAMentos: Capivara, Brasil, 2010; Volume 2, pp. 167-186.

25. Krishna, R.; Kumar, G. Physico-Psychological Approach for Understanding the Significance of Lower Palaeolithic Cupules. In Pleistocene Art of the World; Bulletin de la Societe Prehistorique Ariege-Pyrenees; Proceedings of the Numero Special des Acts du Congress IFRAO, Tarascon-Sur Ariege and Foix, Pyrenees, France, 6-11 September 2010; Clottes, J., Ed.; Pyrenees, France, 2012; pp. 158-160.

26. Krishna, R.; Kumar, G. Understanding the creation of early angular cupules on hard quartzite rock at Daraki-Chattan by direct percussion method: A preliminary study. Purakala 2012, 22, 17-28.

27. Bednarik, R.G. The science of cupules. Rock Art Res. 2016, 33, in press.

28. Bednarik, R.G. The tribology of cupules. Geol. Mag. 2015, 152, 758-765.

(C) 2015 by the authors; licensee MDPI, Basel, Switzerland. This article is an open access article distributed under the terms and conditions of the Creative Commons Attribution license (http://creativecommons.org/licenses/by/4.0/). 